\title{
Social Work Programs' Use of the World Wide Web to Facilitate Field Instruction
}

\author{
Jerry Finn \\ Steven M. Marson
}

\begin{abstract}
Employing a systems model, this study presents a content analysis of the Websites of social work academic programs in the United States. A sample of 292 academic programs was extracted from the Baccalaureate Programs Directors' (BPD) online directory of CSWE-accredited social work programs. Of these, 119 were MSW or MSWIBSW programs; the remaining 173 were BSW programs. Although many aspects of Website content were examined, field curriculum was the central focus of this study. The results demonstrate the wide variety of information included on the Websites. MSW and MSWIBSW program Websites offer more information than BSW programs. However, most programs are not making use of the Internet to obtain feedback, create interaction, or provide support. A variety of model Websites are offered to assist social work academic programs develop and maintain their own Websites.
\end{abstract}

Keywords: Internet, Web, social work education, field education, systems theory

1 The World Wide Web is emerging as a powerful and indispensable tool for accessing human service-related information. Human service agencies are increasingly using it as a means of providing agency information as well as data about community education, advocacy, fundraising, and volunteer recruitment (Finn, 1998; Geiss \& Viswanathan, 1986; Marson, 1998; Schoech, 1999; Young, 1997). Social work education programs are integrating information technology into their curriculum and creating Web sites that provide information about their programs, link social workers to other information resources, and teach students information technology skills (Finn, 1988; Finn \& Lavitt, 1995; Finn \& Smith, 1997; Hooyman, Nurius \& Nicoll, 1990; Hudson, 1993). While the majority of social work programs have their own Website, there is little research available that examines the goals, content, or student, agency, and faculty satisfaction of Website offerings.

This paper focuses on the use of the World Wide Web by social work programs as a means to provide information to students, human service agencies, and the larger community about the program's field education component. Using a general systems model (Carter \& Anderson, 1990), the field curriculum can be viewed as a system involving the dynamic interaction of the social work program, agency place-

Jerry Finn, Ph.D. is Professor, Department of Social Work at the University of New Hampshire. Steven M. Marson, Ph.D., A.C.S.W. is Director and Professor, Social Work Program, University of North Carolina at Pembroke.

Copyright@ 2001 Advances in Social Work Vol. 2 No. 1 (Spring 2001) 26-37.

Indiana University School of Social Work. 
ment sites, and students (Bogo \&Vayda, 1998; Collins, Thomlinson \& Grinnel 1992; Kerson, 1998; Royse, Dhooper \& Rompf, 1998). It is a system where open communication and feedback are essential to maintaining a quality field component (Webb, 1988). Although Council on Social Work Education (CSWE) accreditation requires that certain information, such as program mission and goals, becomes readily available to all members of the system, programs vary in the quantity and quality of field-related information that is made available and to whom this information is accessible.

The information needs of participants in the system can be conceptualized in relation to three primary subsystems: Academic Program, Agency, and Student. The following represents the types of information needed by each subsystem. The list is not comprehensive, though, since programs and agencies may have esoteric information needs to facilitate their mission.

All members of the system need academic program information that include the program's overall mission and goals and, specifically, information on the field component. In addition, system members must understand the relationship of the mission and goals to specific policies and procedures related to field internships. To achieve a successful field program, mechanisms for ensuring the distribution of program information to all system participants, updating changes in such information, and receiving feedback about the academic program must be in place.

Agency-related information about placement sites includes agency mission, client population served, intervention theories and methods, field instructor experience and training, available learning opportunities, expectations for travel, liability insurance needs, expected work schedules, and other agency-specific expectations. The field staff needs this information in order to evaluate potential field placements and to appropriately match students with field placements. Agency information may or may not be available to students. There are a number of advantages to making such information available to students. This information promotes exploration of placement choices, provides education about the variety of agencies and services available in the program's locale, and gives students a greater sense of participation and empowerment. Agencies, per se, should have access to agency information to ensure that it is up-to-date and accurate. In addition, access to all agency information may be useful for networking or information and serve as a referral guide to local agencies.

Student information includes demographic characteristics, the student's interests and abilities, and on-going feedback about the student's performance at the agency. All constituents also need information about academic support opportunities for students experiencing difficulties. The field staff need information to appropriately place students in settings that best meet their needs. Agencies and other students are generally not given access to student information in order to protect student privacy. Basic information, such as a student's interests and placement sites, however, may serve a networking purpose for both the student and agencies.

Systems require effective communication, mutuality, and feedback in order to function optimally. The program's field component must have a mechanism that 
can assess both the process and outcomes of field activities from all constituents. Traditionally, information and feedback has been provided to agency personnel and students through orientation sessions, a field manual, and meetings between the student, advisors, field liaisons, field supervisors, and other faculty.

Use of the Internet, especially the Web and electronic mail, can greatly facilitate and supplement the information and feedback process. Information about the academic program, placement sites, and students can be made available on the Web. In addition, the Web can be used to facilitate communication between faculty, field instructors, and students through e-mail, online discussion groups, and online feedback forms. Theoretically, use of the Web can create an open system with easy access to information for all parties and facilitate a well-designed feedback loop to improve the functioning of all participant subsystems. However, it can also disrupt traditional hierarchical organizational practices. For example, increased information about potential field placement sites may increase students' efforts to lobby field staff for their preferred placement sites. Research that focuses on the extent to which social work programs are making field-related information available on the Website or evaluates the consequences of doing so has not yet been conducted.

This paper describes a content analysis of the field component of social work program Websites. The study examines:

- the number of programs with Web-related field information;

- the types of information available (e.g., program mission, description of placement sites, etc.);

- the extent to which Websites are interactive (use feedback forms, e-mail, or online discussion groups);

- comparisons between online information provided by MSW or combined MSW/BSW programs and BSW-only programs; and

- student ratings related to the usefulness of the Web-based field information.

In addition, recommendations for enhancing the use of the World Wide Web to support field education and model field-related Websites are presented.

\section{METHOD}

This study included all social work programs in the United States with links to a Website $(n=292)$ as listed in the Association of Baccalaureate Program Directors (BPD) Website (http://www.bpdonline.org) during February, 1999. (At that time, CSWE had not yet developed its online directory of programs.) The BPD directory listed 353 social work programs that represent all accredited and in-candidacy social work programs at the time. Of these, $292(82.7 \%)$ had links to the program's own Website or to social work information on the Website of the educational institution in which the program resides. The remaining programs (17.3\%) either did not have a Website or did not offer a Website that contained social work information. For comparison, programs were divided into those offering an MSW or Combined MSW/BSW programs $(n=119)$ and those with BSW only programs $(n=173)$. 
A checklist of informational items was developed based on the types of information found in a review of several field placement policy and procedures manuals. A preliminary review of 10 social work program Websites led to the inclusion of additional informational items in the checklist. Table 1 describes the information items in the checklist. Specific information items were later categorized as falling within two of the three subsystem components: program information and agency information. (The third subsystem, student information, was not found on any of the program Websites). For purposes of clarity and discussion, program information was further divided into "general information" and "policies." In addition, Website components that promote information sharing and feedback were listed under "communication."

Each Website was reviewed by one author and an MSW student research assistant. All information and field-related links on a program's Website were examined. Information items were rated as "present" or "absent." Initial inter-rater reliability was $89 \%$. Items in which there was disagreement were discussed until agreement was reached.

\section{RESULTS}

Table 1 describes the information items and the percent of programs offering each item on their Website. It can be seen that programs varied widely in terms of the types of field information included on their Website. Overall, MSW-only or combined MSW/BSW (MSW) programs offer more information than BSW (BSW) standalone programs. A $\chi^{2}$ analysis was used to test differences in the number of MSW/BSW programs offering more specific information items. Overall, MSW programs were more likely to offer information on $28(68.3 \%)$ of the 41 items. It should be noted that $59.7 \%$ of MSW programs provided separate links or pages with fieldrelated information, while only $17.9 \%$ of BSW programs did so $\left(\chi^{2}=54.05, d f=1\right.$, $p<.001)$. Nevertheless, fewer than $20 \%$ of programs provided more than half the information items on their Website.

Within the subsystem program information, general information includes course syllabi, a calendar of events, field-related forms, an online field manual, and an overview/history of the field program. Approximately half of the programs provide the course syllabi for field and seminar courses, but very little other information is provided. Field policies include information related to the student requirements (e.g., number of courses and hours of field placement); criteria for selecting placements and field instructors; grievance procedures; a description of the roles of the field coordinator, faculty liaison, field instructor, and field advisory committee; and agency issues, such as liability insurance and placement at on-going employment sites. More than three-fourths of the programs provide field requirements on their Website, and about half of the MSW programs describe the criteria for selecting placement sites. The vast majority of programs, however, have no other specific field-related policies on their Website. For example, only $9.2 \%$ of MSW and $2.3 \%$ of BSW programs provide their field policies related to grievance procedures on their Website.

The agency subsystem includes descriptions of placements (e.g., mission, location, size, social problems, etc.), as well as information about agency-related issues, 


\begin{tabular}{|c|c|c|c|}
\hline & $\% \operatorname{Pr}$ & rams & \\
\hline & & MSW or & $\chi^{2}$ \\
\hline & BSW Only & MSW/BSW & $(N=292, \mathrm{df}=1)$ \\
\hline PROGRAM INFORMATION & & & \\
\hline General Information & & & \\
\hline Seminar Course Outline & 55.4 & 58.8 & \\
\hline Field Course Outline & 55.5 & 59.7 & \\
\hline Field Calendar & 0.6 & 14.3 & $22.90^{* * *}$ \\
\hline Separate Field Section/Pages & 17.9 & 59.7 & $54.05^{* * *}$ \\
\hline Field Manual Online & 2.9 & 11.8 & $9.13^{* *}$ \\
\hline Online Forms & 1.2 & 5.9 & $5.72^{*}$ \\
\hline Program History & 2.3 & 8.4 & $5.73^{*}$ \\
\hline Learning Contracts & 0.0 & 6.7 & $11.96^{* *}$ \\
\hline Policies & & & \\
\hline Field Requirements & 76.3 & 90.8 & $10.07^{* *}$ \\
\hline Information for Field Instructors & 1.7 & 17.6 & $23.66^{* * *}$ \\
\hline Field Coordinator's Duties & 3.5 & 12.6 & $8.18^{* *}$ \\
\hline Field Liaison's Duties & 0.0 & 7.6 & $13.50^{* * *}$ \\
\hline Field Instructor's (Agency) Duties & 0.6 & 10.1 & $14.98^{* * *}$ \\
\hline Criteria for Selecting Placements & 15.0 & 50.4 & $42.50^{* * *}$ \\
\hline Grievance Procedure & 2.3 & 9.2 & $6.95^{*}$ \\
\hline Description of Supervision & 0.6 & 10.1 & $18.86^{* * *}$ \\
\hline Liability Issues & 1.2 & 14.3 & $19.98^{* * *}$ \\
\hline Criteria for Selecting Placements & 5.8 & 27.7 & $27.05^{* * *}$ \\
\hline Information Re: Placements at Work & 0.0 & 11.6 & $22.99^{* * *}$ \\
\hline Field Advisory Committee & 1.2 & 2.5 & \\
\hline AGENCY INFORMATION & & & \\
\hline Description of Individual Placements & 4.0 & 10.9 & $5.23^{*}$ \\
\hline Searchable Database of Agencies & 0.0 & 4.2 & $7.40^{* *}$ \\
\hline Listing by Social Problem & 1.7 & 5.9 & \\
\hline Placements by Geographical Location & 2.9 & 4.2 & \\
\hline Placements by Alphabetical & 7.5 & 21.0 & $11.34^{* * *}$ \\
\hline Directions to Agency & 0.6 & 0.0 & \\
\hline Transportation Issues & 1.7 & 5.9 & $7.62^{*}$ \\
\hline Disability Issues & 0.6 & 3.4 & \\
\hline Provides a Stipend & 0.0 & 3.4 & $5.90^{*}$ \\
\hline Direct Link to Placement URL & 2.3 & 4.2 & \\
\hline Number of Students Accepted at Agency & 0.6 & 1.7 & \\
\hline COMMUNICATION & & & \\
\hline E-mail Link to Field Director & 9.2 & 26.9 & $15.98^{* * *}$ \\
\hline E-mail Link to Field Liaison/Advisor & 1.7 & 12.6 & $14.40^{* * *}$ \\
\hline Feedback Form & 2.3 & 5.0 & \\
\hline Faculty Names & 62.4 & 88.2 & $23.79^{* * *}$ \\
\hline Faculty Phone Number & 23.7 & 34.5 & $4.03^{*}$ \\
\hline Faculty E-mail Link & 34.1 & 59.7 & $18.65^{* * *}$ \\
\hline Liaison E-mail Link & 1.7 & 12.6 & $14.40^{* * *}$ \\
\hline Faculty Office Address & 18.5 & 25.2 & \\
\hline Online Field Discussion & 1.2 & 4.2 & \\
\hline Newsletter, Articles, Publications & 1.7 & 2.5 & \\
\hline USEFULNESS RATING (4 OR 5) & & & \\
\hline Score of 4 or $5=$ Highly Useful & 4.1 & 18.9 & $16.40^{* * *}$ \\
\hline
\end{tabular}


such as the need for transportation and whether the agency pays a stipend. Most programs do not provide agency-related information on their Website. Only $20 \%$ of MSW programs and fewer than $10 \%$ of BSW programs provide a listing of field placement sites. Very few programs, generally fewer than $10 \%$, provide agency descriptions or other agency-related information. Finally, only $4.2 \%$ of the programs offer a searchable online database of field placement sites.

The Internet can be more than a static provider of information. It can be used to promote communication, interaction, and community among participants of a system. As noted in the communication section of Table 1, this trend is starting to occur in a small number of programs. Approximately $25 \%$ of MSW programs and $10 \%$ of BSW programs provide an e-mail link to the field coordinator within a separate field-related page. E-mail links to all faculty are provided by approximately two-thirds of MSW programs and only one-third of BSW programs. It should be noted that less than half of the programs identify and provide e-mail links to faculty liaisons. Generally, programs do not actively solicit feedback from students or agencies through their Website. Only 5\% of MSW programs and $2.3 \%$ of BSW programs provide an online form that asks for feedback, comments, or questions. Similarly, only a few programs provide an online discussion group where faculty, students, and agency personnel can discuss issues related to field placement. Finally, the Website is generally not used as an additional communication channel to publish program newsletters and bulletins related to field placement.

The usefulness rating came about as two MSW students rated the program Websites in terms of their overall usefulness of the information provided with respect to the program's field component. The students were quite computer literate and had high expectations of how Websites can be used by social work programs. They rated each site on a five-point scale from one (not at all useful) to five (highly useful). Raters were in agreement on $84 \%$ of ratings and within one point on $94 \%$. In cases of disagreement ( $16 \%$ of ratings), raters' scores were averaged. Overall, student ratings reflect the lack of field information available on program Websites. The mean ratings were 2.52 for MSW or combined MSW/BSW programs $(S D=1.25)$ and $1.54(S D=.94)$ for BSW programs. ANOVA found these differences significant $(F=58.729, d f=1, p<.000)$. Only $18.9 \%$ of MSW program and $4.1 \%$ of BSW program Websites were rated highly useful (four or five). More than half of all Websites $(53.1 \%)$ were rated as "not at all useful" in terms of providing field information.

\section{DISCUSSION}

Social work programs have begun to use the Internet to supply information about their programs, and a majority of programs include some information about the field component. It appears, however, that as of April, 1999, most programs were not making optimal use of their Website. Schoech (1999) described three phases of technological change. In the first phase, new technology is used in ways similar to those of the old method. In the second phase, improvements are made so that new technology improves the way things have been done in the past. In the third phase, new technology results in the creation of new systems, products, and methods that were previously impossible. It appears that in using Websites, most programs fall somewhere between the first and second phase. The Web is used as a one-way 
publication tool to provide information generally available in paper form. There are improvements in access to the information, but they may not impact system functioning because the information is often incomplete and no improvement in the feedback loop is achieved.

Social work field programs may not be making optimal use of program Websites for a number of reasons. Resource issues may play an important role in determining the content of social work Websites. In this study, resources for Websites were not directly measured. It can be noted, however, that programs that included an MSW degree were more likely to offer more content and more interactive options than BSW programs. Overall, MSW programs are larger, better funded, have more faculty, and are more likely to have university support for technology than BSW programs. On the other hand, with BSW-only programs, being smaller, they may have more direct face-to-face contact with students and may find less need to provide information on the Web. The reasons for the differences in Web-based content warrant further study. Although MSW program Websites offer relatively more information and were rated by students as more useful, most MSW programs still include only a small fraction of the content that might be found in a comprehensive system.

\section{Recommendations}

Social work programs interested in using the Web to its fullest extent must begin to strategically plan to obtain the personnel, software, and training resources necessary to create and maintain a Website. The cost of these resources has decreased dramatically during the past few years. Most programs already have a Website, Internet access, and server space available through their university or college. Software that allows Web pages to be created without the need for writing Hypertext Markup Language (HTML) code is now readily available and affordable. Many word processing programs convert documents to HTML-based Web pages, allowing for the easy creation of simple Web pages. Commercial software designed to convert large documents (such as a field manual) to HTML is also available and provides automatic indexing and linking of the contents. Other software allows programs to put large documents on the Web in .pdf format, making it easy to read online and easy to download or print in a usable format. Database software enables programs to maintain an electronic record-keeping system with student, agency, and field instructor information organized in ways that are convenient for the program. Many of these programs produce reports in HTML that can be used directly on the Web. Finally, given the ubiquity of Web development, there may be work-study students or even volunteers who are willing to work on social work program Websites. For those few programs that do not have campus-based Internet resources, a commercial Internet Service Provider is now within the budget of even the most severely limited programs. Several Internet sites now offer free Web space and e-mail accounts to subscribers. Resource issues alone do not explain the limited use of the Internet by social work field programs.

Matheson (1993) notes that among human service agencies, a "computer champion"-someone who enjoys working with technology and encourages the agency to use it-can be instrumental in advancing information technology development. Social work programs should be encouraged to find or support the devel- 
opment of such a "computer champion." At the same time, field coordinators and other interested faculty must advocate for field-related information to be made available online. In this study, almost $40 \%$ of MSW programs and more than $80 \%$ of BSW programs did not have separate areas devoted to field information. Including field information on the Web, in part, is a matter of consciousness. Field staff must begin to include the program's Website in all aspects of their planning and communication activities.

Successful Websites offer content users need, are updated regularly, provide a degree of interactivity, and are designed to be easy to read and navigate (Wiggins, 1995). The majority of social work programs have not yet taken advantage of the Web's potential to promote communication and feedback. This can be achieved in a number of ways. Programs can link students and the community through e-mail to all personnel involved in the field program, including the field coordinator, faculty liaison, seminar instructor, students in placement, and, when possible, the agency field instructor. Students can be required to have e-mail addresses as a program requirement, and field instructors without e-mail addresses can be provided with Internet options for obtaining free e-mail. Field liaisons can require weekly or bimonthly progress reports by e-mail. In addition, programs can invite constituents to e-mail their questions and feedback. An online feedback form is a convenience to users, although not all servers allow use of online forms for security reasons. Programs can create specific online discussion groups to address field placement issues. This may serve as an additional source of information and feedback as well as a potential additional source of online support for students. A separate discussion group or electronic mailing list for field instructors would provide another avenue for communication. In many universities and colleges, such groups can often be set-up through a simple request to the Information Technology unit. Open and ongoing communication about field issues can create synergy for program development.

\section{Model Websites}

Field components of social work programs may not be making optimum use of their Websites due to lack of exposure to successful Website models. The Council on Social Work Education maintains an online list of social work programs with links to their Websites (http://www.cswe.org/directory). No organization, however, has yet been known to evaluate and rate the quality of social work Websites. In this study, a number of program sites were rated as " 4 or 5 " for overall usefulness by two students. While space prohibits a description of all such sites, the following list (in alphabetical order) offer models of field Website components that could serve as good examples of field education online.

Colorado State University (www.colostate.edu/depts/socwork) provides a directory of field agencies based on social problems and includes detailed agency information. The site also provides a field calendar, field forms, and links to field faculty.

Florida State University (http://ssw.fsu.edu/field/fieadm.html) provides course outlines for field courses, detailed information about clinical and administrative field tracks, online field policies featuring a separate area describing policies regarding termination, a field calendar of events, and links to field faculty. 
New Mexico State University (http://www.nmsu.edu/ socwork/field.htm) provides an online field manual with an extensive appendix of forms the field program uses. It also includes an article on using PCs for advocacy, information and referral, and networking that was published in the MSW and BSW field manuals.

Salisbury State University (http://www.ssu.edu/Schools/Seidel/SocialWork/ field.html) provides their field manual in PDF format, along with a link to obtaining the Acrobat Reader.

Syracuse University (http://www.social.syr.edu/fieldsearch/) provides a "field placement locator" that allows students to search for placements based on geographic location, social problem, and level of student (e.g., first year). The search results provide a brief agency description and information about transportation, availability of placements, special requirements, and other agency information. Graduate and undergraduate field manuals are also available online. The site also has a "Guest Book" that requests feedback about the Website or program.

University of Kansas (http://www.socwel.ukans.edu/email/directory.html) provides an online e-mail directory to all students, instructors, liaisons, and staff, although this is not directly associated with a field-related page.

University of Maryland (Baltimore County) (http://novell.umbc.edu/socialwork/ fieldl.htm) also provides its field manual online. A table of contents includes links to many of the sections. In addition, a separate field instruction calendar is available.

University of Michigan (http://www.ssw.umich.edu/ofi/) provides extensive field information, including a password-protected listing of agency availability, an excellent FAQ (Frequently Asked Questions) section, and a comprehensive online field manual. They also provide online forms for students, agencies, and field instructors in PDF format.

University of Missouri (http://web.missouri.edu/ sswmain/field.html) provides an online database of field agencies that can be searched or browsed. The database includes a description of services, directions, number of placements available, and other agency-related information. The program also provides a number of password-protected forms that can be filled out online, including a field instructor feedback form.

University of North Carolina-Pembroke: (http://www.uncp.edu/sw/fieldexp.html) provides a field handbook that includes the history of the program, policies and procedures, and online forms. Field placement agencies available by geographic area, social problem, and alphabetical listing are featured, complete with descriptions. This is a good example of displaying agencies without using a search engine.

University of Texas-Arlington (BSW and MSW) (http://www2.uta.edu/ssw/field.htm) provides a separate field section that includes a link to the field director, links to affiliated agencies with Websites, and a summary of field-related academic information. There is an excellent search page that uses drop-down menus in which agencies can be searched by area of practice, geographical area, and level of student (e.g., undergraduate). In September, 1999, a counter noted that the page had been accessed 26,000 times since April, 1998. 
University of Vermont-(http://www.uvm.edu/ socwork/field/Field_Instructor_ Recruitme.htm) provides an online field manual for both MSW and BSW programs. In addition, the site lists the field agencies available, including the number of placements available and the type of students accepted.

\section{Limitations of the Study and the Need for Further Research}

The use of Web-based information may promote field education that enhances communication, feedback, and system change. This paper describes the extent to which programs utilize various information technology components in their Website, but does not address the outcomes of having such components.

Systems theory assists in conceptualizing the mutuality among cooperating social systems. The following are some key system outcomes that might emerge from a program's extensive use of the Web.

- After initial capital outlay, the academic program can provide all information required by the other social systems, with significantly less cost than any other form of information dissemination used in the past.

- Information is timely. When critical (and non-critical) information changes, databases, and Websites can be updated immediately at little financial cost. Academic programs and agencies no longer must wait an entire fiscal year to provide updated information - as has been done in the past. Thus, the system's information needs are met with a speed hitherto not witnessed in our academic/practice history.

-When a technological change takes place within one system, it enhances the probability of corresponding changes with other interdependent systems. For example, if students and the academic programs employ technology to complete tasks and disseminate information, agencies will eventually follow.

- New technology provides a basis for greater mutuality, communication, and cooperation. For example, e-mail makes communication easier. Thus, parties communicate with each other with greater frequency and problem solving is enhanced. Similarly, since feedback through e-mail and online forms is more frequent, program change and development is more ongoing and responsive.

There is yet no evidence, however, that programs with a comprehensive Website have better field-related outcomes or that student and agency satisfaction with the field is higher. Further research is needed to evaluate the impact of providing a comprehensive Website on the overall functioning of the program, including the types of organizational and programmatic improvements and/or disruptions that occur as we move toward ever more open systems through technology.

This study focused on the content of field Websites and has an underlying bias that "more information is better." Other factors, however, such as overall visual appeal, organization, ease of use, accuracy and timeliness of information, and ease of access may be equal or more important in determining the quality and usefulness of program Websites. Research is needed to assess the utility of various models for providing field information online.

In the past, the authors have hypothesized that a lack of resources may be related to the limited amount of information provided by some program Websites. This 
study did not address the correlation between resources and the ability to utilize the Web to provide information. Lack of resources is not the only reason, however, that some programs make relatively little use of the Web. Information may create difficulties for the program. Students who can search agency placement information may be more likely to want to select their own placements. Field instructors with e-mail access to the field director may want to discuss a student's problematic behavior more frequently. Students who can readily search the policy manual and have easy access to communication with fellow students and field instructors may be more likely to electronically organize campaigns to change current program policy. While all these actions can be seen as "healthy" for a system, they can create disruption and stress resources. The extent to which online social work program information is problematic is unknown and further research in this area is warranted.

The satisfaction of students with program Websites is based on the ratings of two computer literate MSW students. While their ratings had high agreement, it is not known to what extent they reflect the satisfaction of most social work students with Websites in their own programs. Other students may have lower expectations of program Websites or may find the information currently provided more useful than did the raters in this study. Each social work program, including the program's field component, must begin to evaluate its Website as an integral part of program evaluation activities.

\section{CONCLUSION}

Social work programs have only begun to use their Websites to meet the information and communication needs of all members involved in the educational process. While field education is only one component of social work education, it is significant and must be included in developing new information technology resources. Professional organizations such as CSWE and BPD could facilitate the development of Web-based information by providing guidelines for what should be made available online and linking programs to model sites that have been peer-evaluated.

This study is a content analysis of field information provided by social work program Websites at a given point in time. Considering the rate of technological change, the information is likely to be quickly out-of-date. However, the issues it raises about what programs offer on the Web, how information is delivered, differences between larger and smaller programs in their ability to provide information resources, the need to plan information resources strategically, and the impact of information technology on program outcomes will increasingly become concerns of social work education. Social work is in an exciting time of development and there is much work to be done.

\section{References}

Bogo, M., \& Vayda, E. (1998). Practice of field instruction in social work: Theory and process. NY: Columbia University Press.

Carter, R.E., \& Anderson, I. (1990). Human behavior in the social environment: A social systems approach (4th ed.). NY: Aldine de Gruyter.

Collins, D., Thomlinson, B., \& Grinnel, R.M. Jr. (1992). The social work practicum: A student guide. Itasca, IL: Peacock. 
Finn, J. (1988). Microcomputers in private, nonprofit agencies: A survey of trends and training requirements. Social Work Research and Abstracts, 24(1), 10-14.

Finn, J. (1998). Seeking volunteers and contributions: An exploratory study of nonprofit agencies on the Internet. Computers in Human Services, 15(4), 39-56.

Finn, J., \& Lavitt, M. (1995). A survey of information technology-related curriculum in undergraduate social work programs. Journal of Baccalaureate Social Work, 1(1), 33-41.

Finn J., \& Smith, M. (1997). The use of the World Wide Web by undergraduate social work education programs. Journal of Baccalaureate Social Work, 3(1), 71-74.

Geiss G.R., \& Viswanathan, N. (Eds.). (1986). The human edge. NY: Haworth.

Hooyman, N., Nurius, P.S., \& Nicoll, A.E. (1990). The perspective from the field on computer literacy training needs. Computers in Human Services, 7(1/2), 95-112.

Hudson, W.W. (1993). The future of social service computing. Computers in Human Services, 10(2), 1-8.

Kerson, T.S. (Ed.). (1998). Field instruction in social work settings. NY: Haworth Press.

Marson, S.M. (1998). Major uses of the Internet for social workers: A brief report for new users. Aretê, 22(2), 21-28.

Matheson, A.D. (1993). Innovative use of computers for planning in human service organizations. Computers in Human Services, 9(3/4), 383-395.

Royse, D.D., Dhooper, S.S., \& Rompf, E.L. (1998). Field instruction: A guide for social work students. Reading, MA: Addison-Wesley.

Schoech, D. (1999). Human service computing. NY: Haworth.

Webb, N.B. (1988). The role of the field instructor in the socialization of students. Social Casework, 69, 3540.

Wiggins, R.W. (1995). The internet for everyone. NY: McGraw-Hill.

Young, J.E. (1997). Building organizational capacity with technology: A strategy for assisting grass-roots environmental groups with computers and telecommunications online. Available: Environmental Support Center, July 21, 1998, [On-line] [Available]: http://www.rffund.org/camp/escpub.html.

\section{Author's Note:}

Address correspondence to: Jerry Finn, Ph.D., Department of Social Work, Murkland Hall, 15 Library Way, Durham, New Hampshire 03824-3596 USA, jerry.finn@unh.edu. 


\section{(eve \\ Advances in Social Work}

Advances in Social Work: Linking Research, Education \& Practice is a professional, refereed journal published twice each year (Fall and Spring) by the Indiana University School of Social Work. An annual subscription is $\$ 30.00$, which includes postage by surface mail.

Payment may be made by check or money order, payable in US funds, to:

Indiana University School of Social Work.

Send your subscription request to:

Advances in Social Work

Subscription Request

Indiana University School of Social Work

902 West New York Street, Suite ES4138

Indianapolis, Indiana, 46202-5156 USA

Advances in Social Work

Subscription Request Form

Name:

Address:

Address:

City, State/Province:

Country:

Postal Code:

Enclosed: $\$ 30.00 \_$Regular Annual Subscription 